\title{
Design and Analysis of Heat Exchanger for Determined Heat Transfer Rate (Multi Model Optimization Procedure)
}

\author{
Subham Sekhar Sahoo \\ ${ }^{1}$ Master of Technology in Power Plant Engineering \& Energy Management, \\ Final Year Department of Mechanical Engineering. \\ O P Jindal University-496109.
}

\begin{abstract}
Heat exchanger as the name indicates it transfers heat from one fluid to another which are at changed temperatures. Heat exchangers are devices built for efficient heat transfer from one fluid to another and are widely used in engineering processes. Some examples are intercoolers, pre-heaters, boilers and condensers in power plants. The heat transfer efficiency depends on both design of heat exchanger and property of working fluid. Some important design parameters such as the pitch ratio, tube length, and tube layer as well as baffle spacing. In this project, the heat transfer efficiency is improved by implementing the full baffle design and travel tube design and analyzing it through CFD flow simulation to find the approximate heat transfer rates. From thesimulation results the optimumbaffledesign and travel tube design for maximum heat transfer rate is identified. Also this project deals with find the suitablefluid for maximum heat transfer rate.
\end{abstract}

Key words- CFD, Heat Exchanger,Baffle Angle.

\section{INTRODUCTION}

A heat exchanger is a device used to transfer heat between one or more fluids. The fluids may be separated by a solid wall to prevent mixing or they may be in direct contact. They are widely used in space heating, refrigeration, air conditioning, power stations, chemical plants, petrochemical plants, petroleum refineries, natural-gas processing, and sewage treatment. The classic example of a heat exchanger is found in an internal combustion engine in which a circulating fluid known as engine coolant flows through radiator coils and air flows past the coils, which cools the coolant and heats the incoming air. The order of reference in the running text should match with the list of references at the end of the paper.

\subsection{Shell and tube heat exchanger}

A Shell and tube heat exchanger Shell and tube heat exchangers consist of series of tubes. One set of these tubes contains the fluid that must be either heated or cooled. The second fluid runs over the tubes that are being heated or cooled so that it can either provide the heat or absorb the heat required. A set of tubes is called the tube bundle and can be made up of several types of tubes: plain, longitudinally finned, etc. Shell and tube heat exchangers are typically used for high-pressure applications (with pressures greater than 30 bar and 3 temperatures greater than $260{ }^{\circ} \mathrm{C}$ ). This is because the shell and tube heat exchangers are robust due to their shape.

Several thermal design features must be considered when designing the tubes in the shell and tube heat exchangers: There can be many variations on the shell and tube design. Typically, the ends of each tube are connected to plenums (sometimes called water boxes) through holes in tube sheets. The tubes may be straight or bent in the shape of a U, called Utubes.

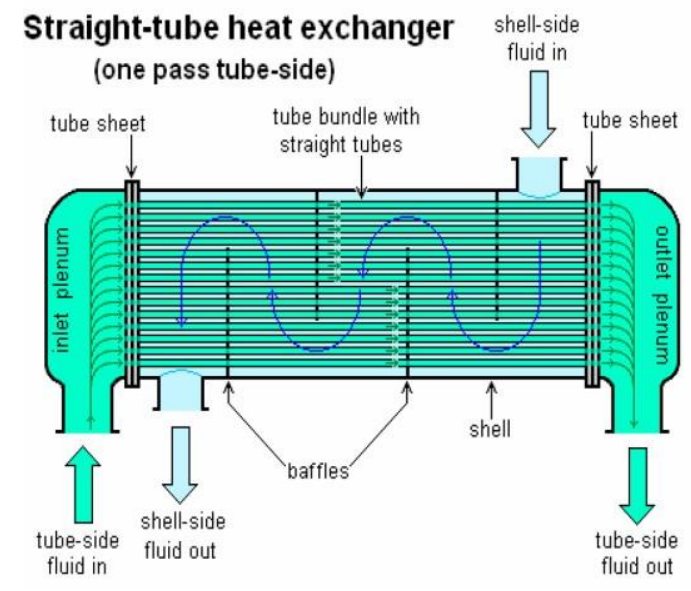

Fig -1: Shell and Tube heat exchanger

\subsection{Baffle Design}

Baffles are used in shell and tube heat exchangerstodirect fluid across the tube bundle. They run perpendicularly to the shell and hold the bundle, preventing the tubes from sagging over a long length. They can also prevent the tubes from vibrating. The most common type of baffle is the segmental baffle. The semicircular segmental baffles are oriented at 180 degrees to the adjacent baffles forcing the fluid to flow upward and downwards between the tube bundles.

Baffle spacing is of large thermodynamic concern when designing shell and tube heat exchangers. Baffles must be spaced with consideration for the conversion of pressure drop and heat transfer. For thermo economic optimization it is suggested that the baffles be spaced no closer than $20 \%$ of the shell's inner diameter. 
2. METHODOLOGY

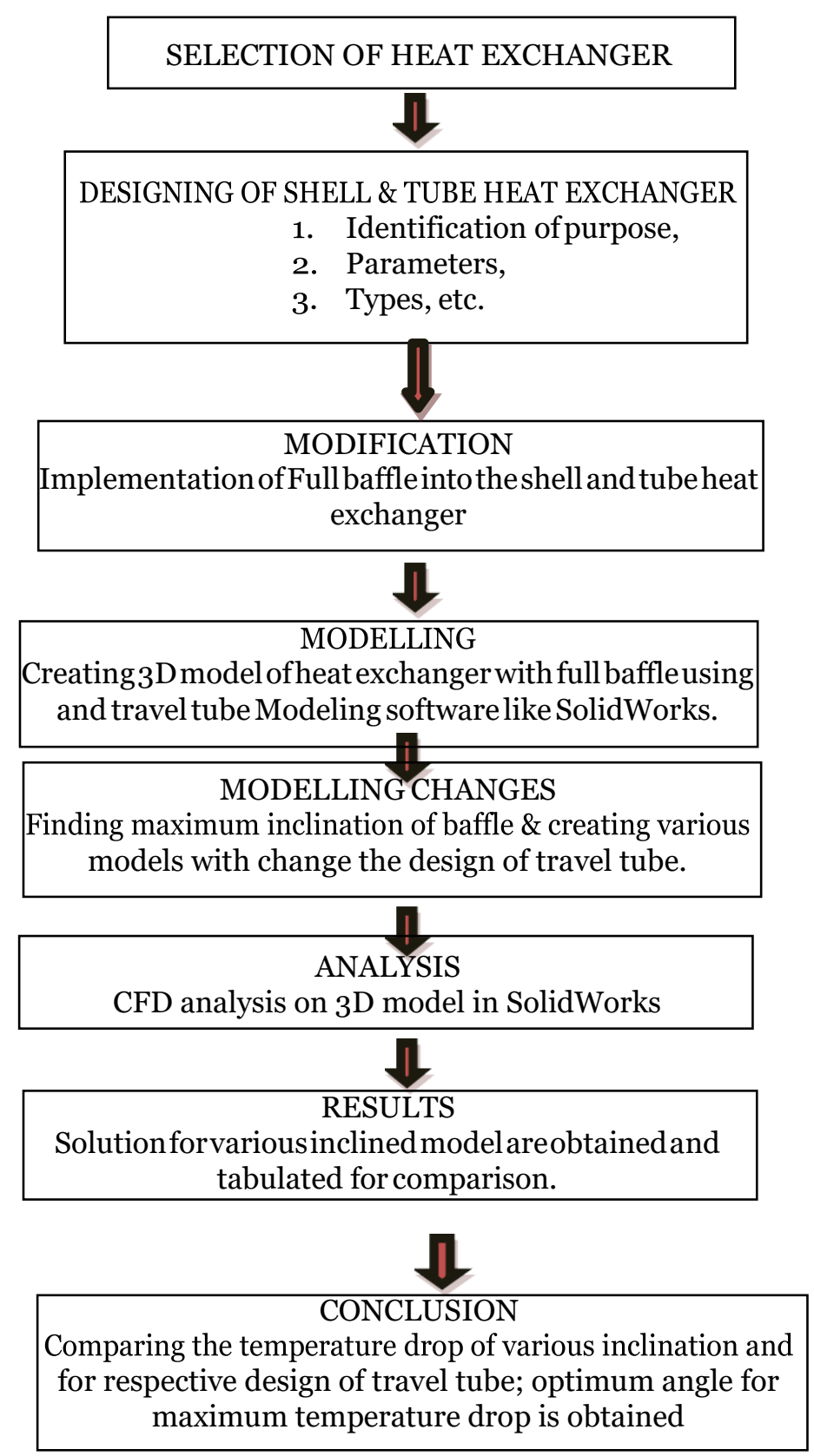

\section{DESIGN AND ANALYSIS}

The shell and tube heat exchanger is designed on the basis of Tube Exchanger Manufacturing Association (TEMA) 1999 procedure.

Table -1: Design of Exchanger

\begin{tabular}{|l|l|l|}
\hline S.No & \multicolumn{1}{|c|}{ Parameter } & \multicolumn{1}{c|}{ Dimension } \\
\hline 1 & Type of heat exchanger & $1-1$ pass shell and tube \\
\hline 2 & Shell diameter & $0.088 \mathrm{~m}$ \\
\hline 3 & Shell length & $0.61 \mathrm{~m}$ \\
\hline
\end{tabular}

\begin{tabular}{|l|l|l|}
\hline 4 & Shell thickness & $0.003 \mathrm{~m}$ \\
\hline 5 & Tube diameter & $0.013 \mathrm{~m}$ \\
\hline 6 & Tube length & $0.61 \mathrm{~m}$ \\
\hline 7 & Tube thickness & $0.001 \mathrm{~m}$ \\
\hline 8 & Tube pitch & $0.023 \mathrm{~m}$ \\
\hline 9 & Tube pitch type & Triangular pitch \\
\hline 10 & Tube clearance & $0.01 \mathrm{~m}$ \\
\hline 11 & Tube diameter ratio & 1.08 \\
\hline 12 & Pitch ratio & 1.76 \\
\hline 13 & Number of tube required & 13 tubes \\
\hline 14 & Number of baffle required & 25 baffles \\
\hline 15 & Baffle spacing & $0.022 \mathrm{~m}$ \\
\hline
\end{tabular}

Pitch type is taken as $60^{\circ}$ triangular to utilize the baffle space effectively.

These design values and procedure are taken from the base paper "Heat transfer enhancement of shell and tube heat exchanger".

\subsection{Model of Heat exchanger}

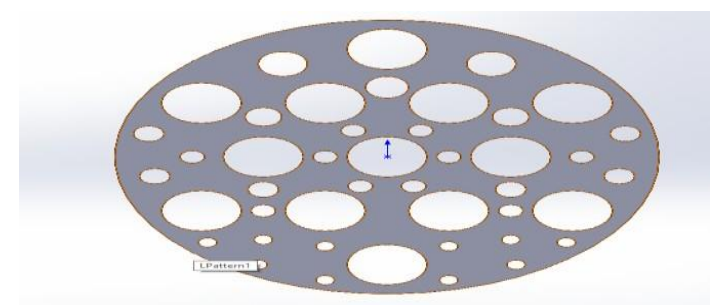

Fig -2: Full baffle for straight tube

Fig -3: Straight travel tube

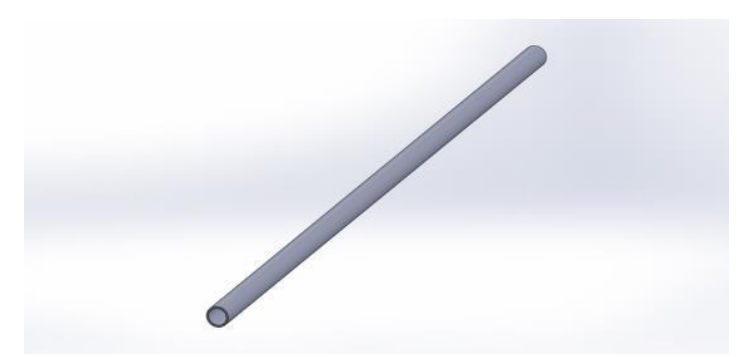

Fig -4: Baffles with tubes \& tube sheet 


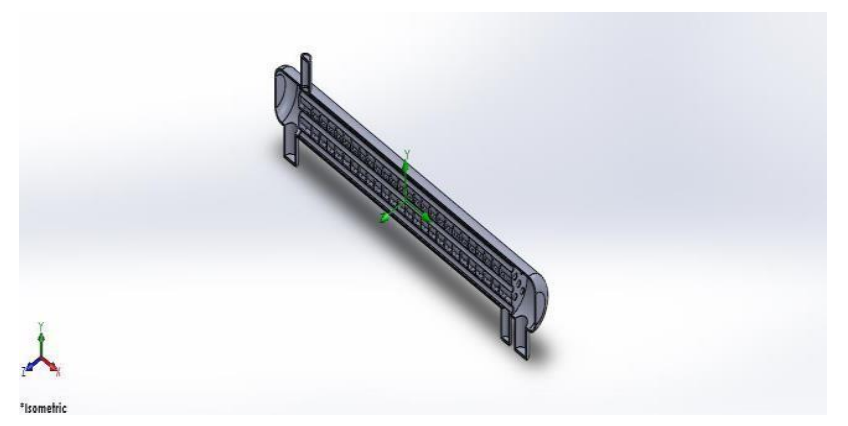

Fig -5: Cut section of heat exchanger

\section{ANALYSIS PARAMETERS}

Fluid: Water

HeatExchanger:-Material-Stainless steel321, Counter flow shell \& tube exchanger.

Initial temperature: Hot fluid $=90^{\circ} \mathrm{C}$ Cold fluid $=26^{\circ} \mathrm{C}$

Flow rate: Hot \& Cold fluid $=0.0027 \mathrm{~m}^{3} / \mathrm{s}$ Environmental Condition: $27^{\circ} \mathrm{C}, 1 \mathrm{~atm} \&$ heat transfer coefficient $5 \mathrm{~W} / \mathrm{m}^{2} \mathrm{~K}$

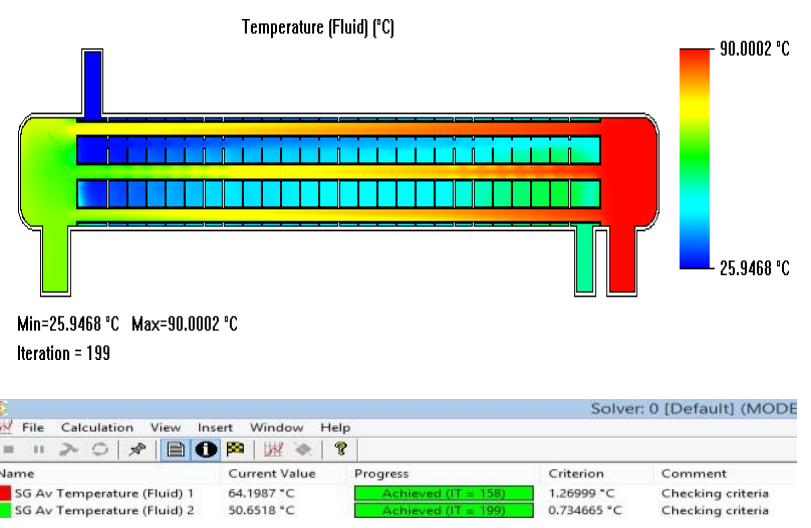

Fig-6:Temperaturedistribution-straightbafflewith uniform tube

5. VARIOUS DESIGN APPROACHES FOR TUBES

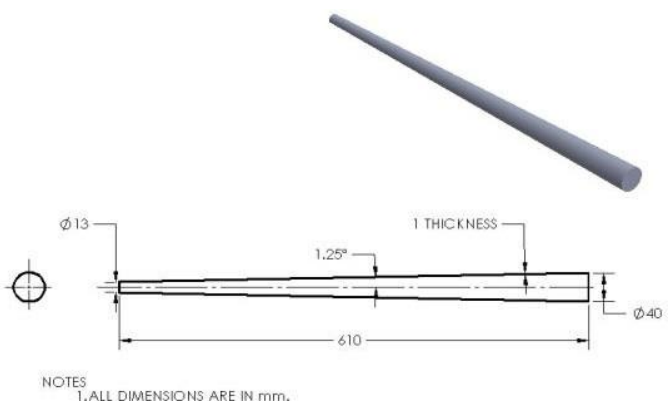

Fig -7: Angled Tube

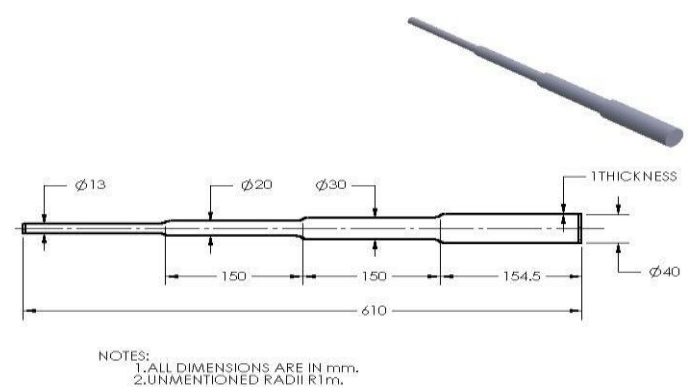

Fig -8: Step Tube

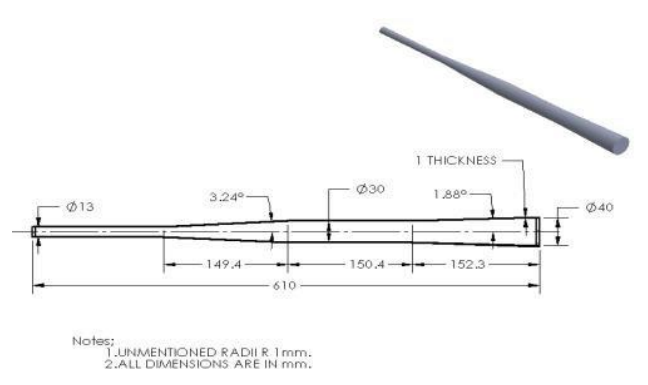

Fig -9: Combine of Angle and Step Tube

\subsection{ANALYSIS OF TUBES}

Heat exchanger parameters taken for analysis

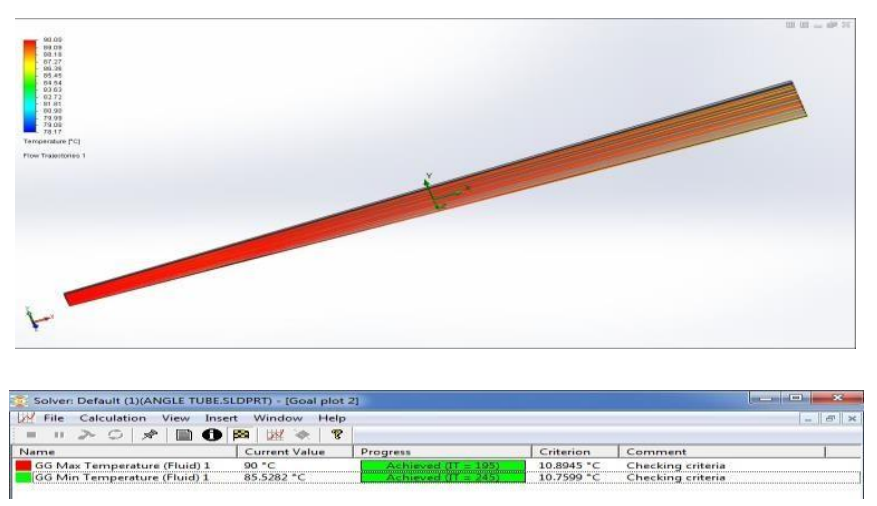

Fig -10: Analysis of Angled Tube min \& max temp values
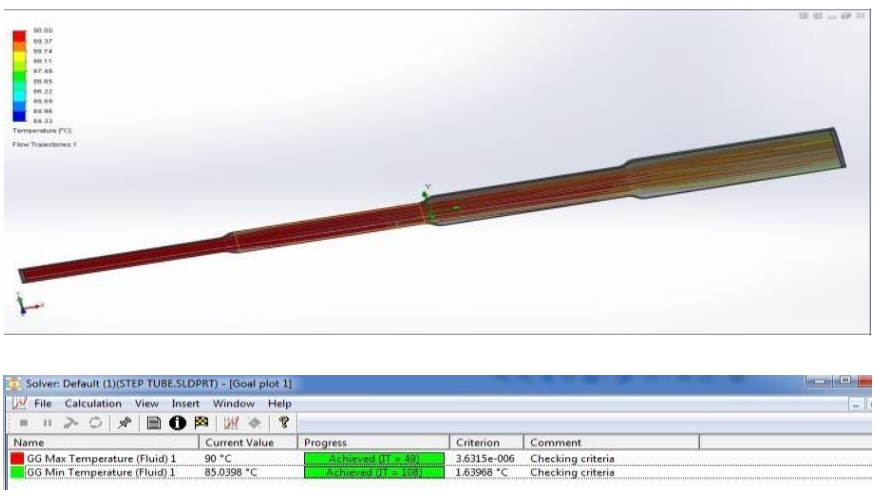

Fig -11: Analysis of Step Tube min \& max temp values 

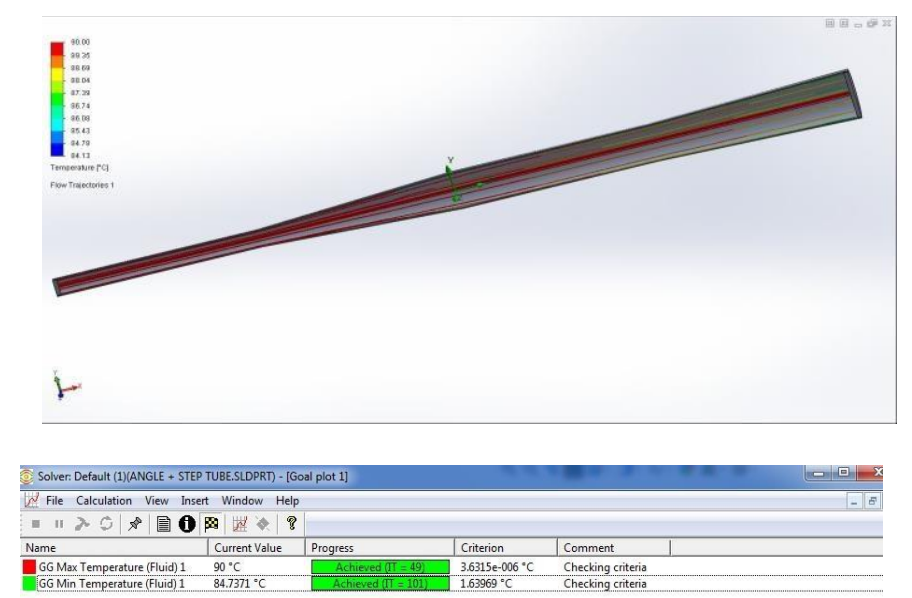

Fig -12: Analysis of Angle+Step Tube min \& max temp values

Table -2: various tube analysis result table

\begin{tabular}{|c|c|c|c|}
\hline Type of tube & In temp ${ }^{{ }_{c}}$ & Out temp ${ }^{{ }_{c}}$ & $\begin{array}{c}\text { Temp different } \\
{ }^{o_{c}}\end{array}$ \\
\hline Normal straight tube & 90 & 88.71 & 1.29 \\
\hline Angle tube & 90 & 85.53 & 4.47 \\
\hline Step tube & 90 & 85.04 & 4.96 \\
\hline $\begin{array}{l}\text { Combine of Angle and } \\
\text { step tube }\end{array}$ & 90 & 84.74 & 5.26 \\
\hline
\end{tabular}

\section{ANALYSIS OF HEAT EXCHANGER BY} ADJUSTING BAFFLE ARRANGEMENTS

Analysis carried out by adjusting the baffle arrangements in the heat exchanger which was done by making it inclined to surface. The angles of inclinations are $5^{\circ}, 10^{\circ}, 15^{\circ}, 20^{\circ}, 25^{\circ}$, $30^{\circ}$ and $35^{\circ}$. it was limited to assembly convenient.

\subsection{Baffle Inclined to 50 :-}

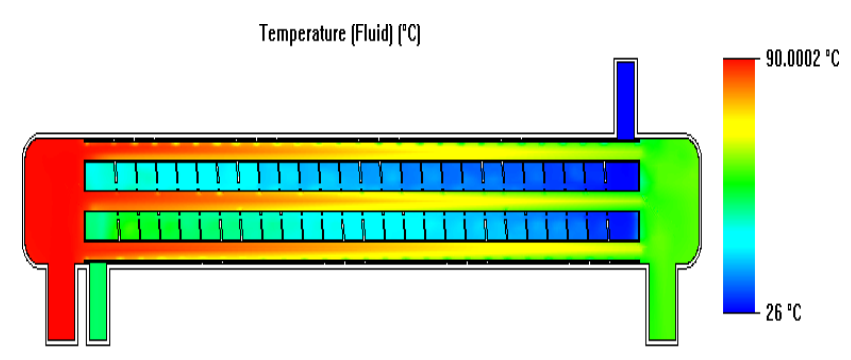

\section{$\operatorname{Min}=26^{\circ} \mathrm{C}$ Max $=90.0002{ }^{\circ} \mathrm{C}$}

Iteration $=245$

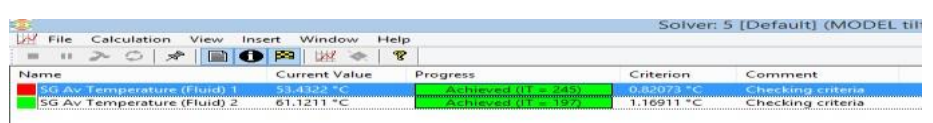

Fig -13: Temperature distribution $-5^{\mathrm{O}}$ inclined baffle

\subsection{Baffle Inclined to $15^{\circ}$ :-}
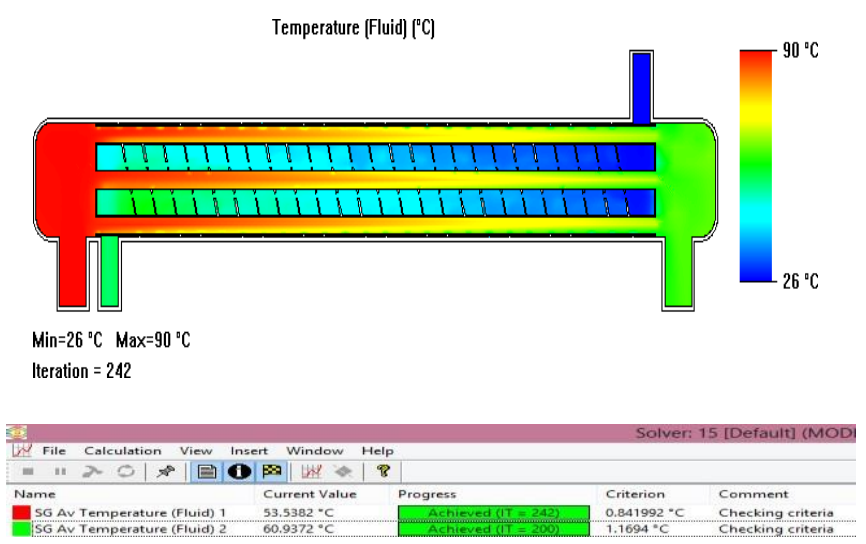

Fig -14: Temperature distribution $-15^{\circ}$ inclined baffle

\subsection{Baffle Inclined to $25^{\circ}$ :-}
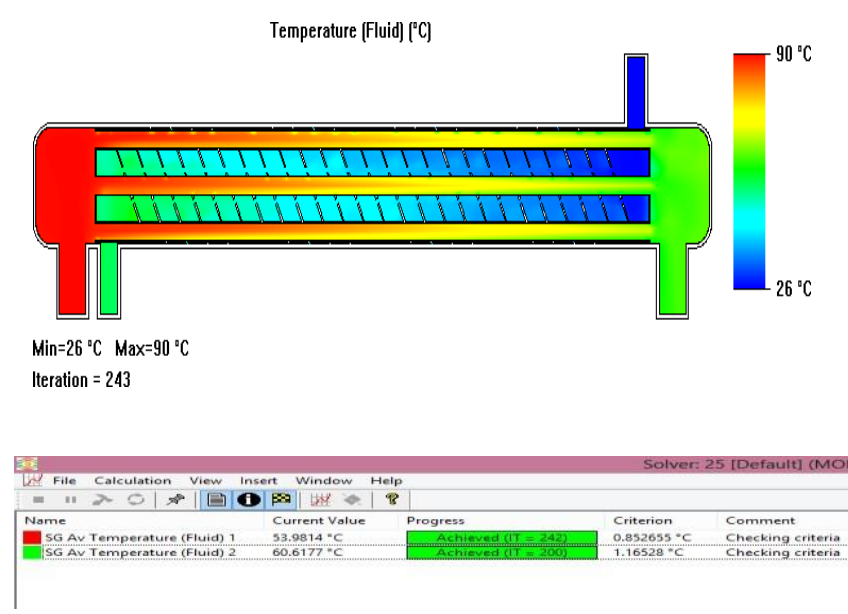

Fig -15: Temperature distribution $-25^{\circ}$ inclined baffle

\subsection{Baffle Inclined to $35^{\circ}$ :-}

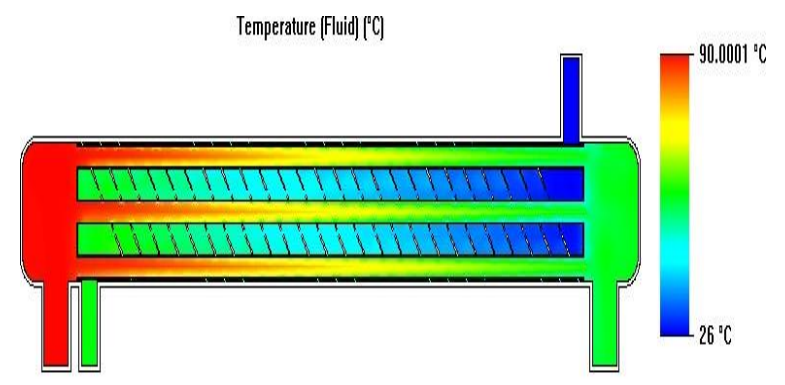

$\mathrm{Min}=26^{\circ} \mathrm{C} \mathrm{Max}=90.0001^{\circ} \mathrm{C}$

Iteration $=281$

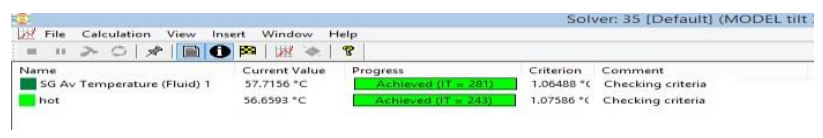

Fig -16: Temperature distribution $-35^{\circ}$ inclined baffle 


\subsection{Temperature drop in ${ }^{\circ} \mathrm{C}$ :-}

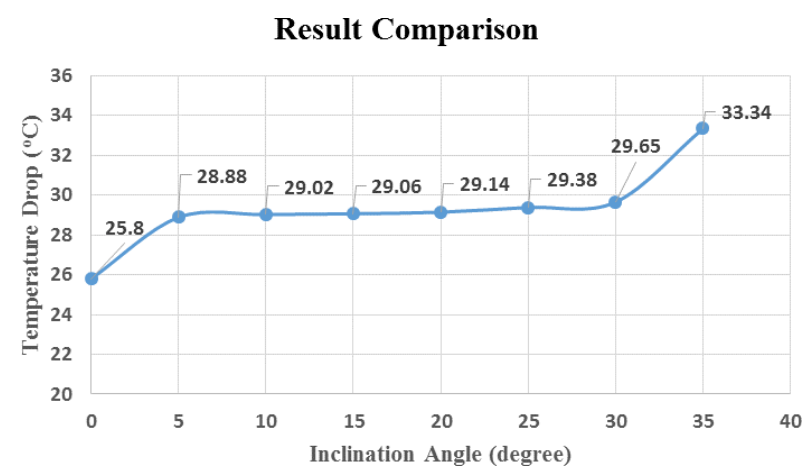

\section{COOLANT FLUID}

A coolant is a fluid which flows through a device in order to prevent its overheating, transferring the heat produced by the device to other devices that utilize or dissipate it. An ideal coolant has high thermal capacity, low viscosity, is low-cost, and is chemically inert, neither causing nor promoting corrosion of the cooling system. From various research journals here we selected $\mathrm{CuO}$ nano structures mixed with water as a coolant for max heat heat transfer rate.

Table -2: Properties Cuo Nano structures

\begin{tabular}{|c|c|c|}
\hline Sl.No & Property & Copper oxide \\
\hline 1 & Thermal conductivity W/mK & 400 \\
\hline 2 & Density $[\rho p] \mathrm{kg} / \mathrm{m} 3$ & 6510 \\
\hline 3 & Specific heat $[\mathrm{Cp}] \mathrm{j} / \mathrm{kg}-\mathrm{K}$ & 540 \\
\hline
\end{tabular}

\section{FINAL DESIGN CONSIDERATION}

- $\quad$ Heat exchanger straight flow tube was replaced by Combine of Angle and step tube. It gives good thermal transfer capacity compared old straight tube and other design's of tubes. It was obtained by computational flow analysis.

- Baffle arrangement modifications also decides the heat transfer rate. The analysis carried out for making it inclined to the flow of hot fluid in the way of $50,10 \mathrm{o}, 15 \mathrm{o}, 20$ $\mathrm{o}, 25 \mathrm{o}, 30 \mathrm{o}$ and $35 \mathrm{o}$.

- $\quad$ From the baffle arrangement flow analysis results the 35 o inclinations of baffle gives good heat transfer rate comparing other inclination angles.
Properties, and Potential Applications - International Scholarly Research Notices, Volume 2014, Article ID 856592 ) it was more efficient coolant compared other medium of coolant.

\subsection{Final Design}

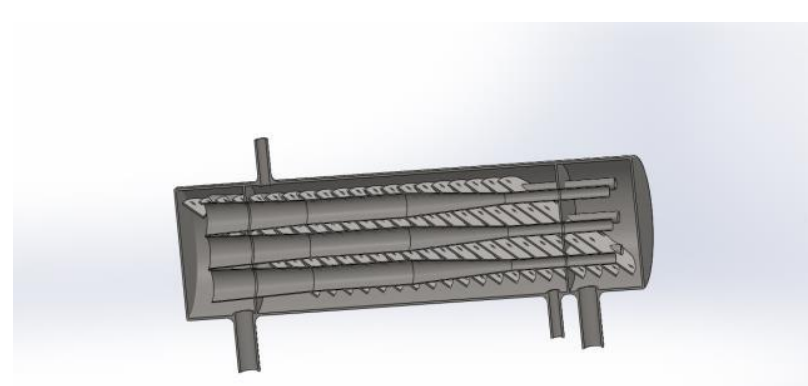

Fig -17: Final effective model

\subsection{Final Analysis}
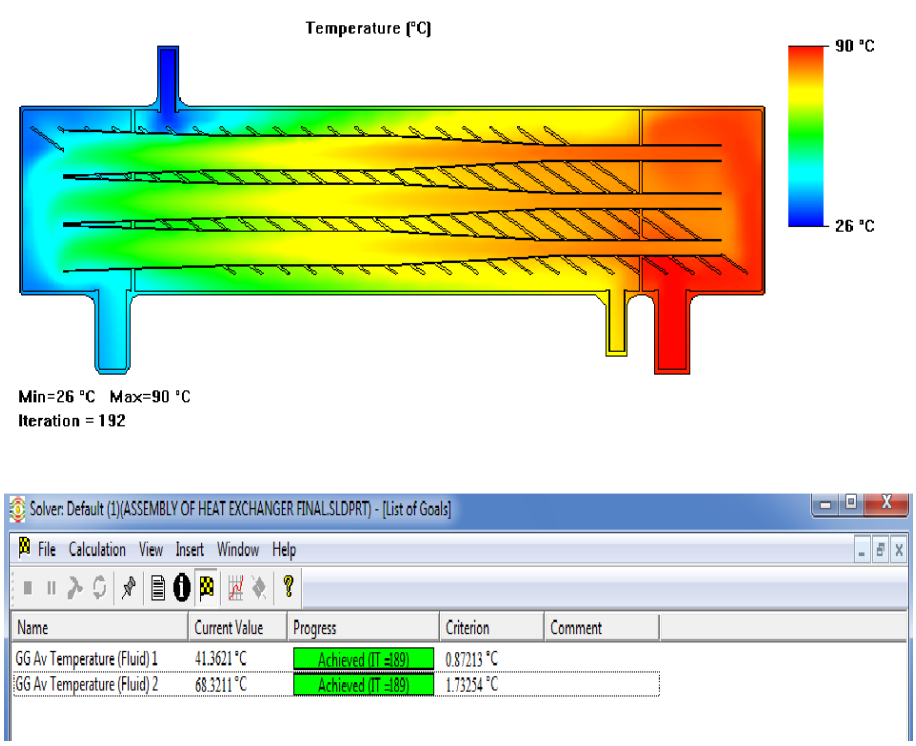

Fig -18: Final analysis

\section{RESULTS}

Oxide Nanomaterials Prepared by Solution methods, Some

- $\quad \mathrm{CuO}$ nano particles was selected as a coolant fluid which was added with water and used as a coolant medium.

- $\quad \mathrm{CuO}$ nano particles was cheap and easily available Also from the latest research results ( Copper 
- $\quad$ The flow simulation analysis is carried out for various baffle arrangement heat exchangers and maximum heat transfer angle of the baffle arrange was found by result comparison from the comparisons of the result 350 baffle arrangement gives better heat transfer results.

- $\quad$ For maximum heat transfer rate theflow tubedesign was changed and best design was found by multi model optimization method. From the basic flow analysis results the angle and step tube combined design was gives maximum temperature drop results. So that type of flow tube was selected.

- $\quad$ From thelatestjournals coolantfluid wasselectedas a $\mathrm{CuO}+$ Water and their properties were given while making the final analysis of heat exchanger.

- $\quad$ Finally the baffle was attached with our selected flow tube and placed inside the heat exchanger and analysis was carried out. From that analysis result temperature drop of the working fluid (water) is obtained and which was gives good results over previous results.

\subsection{Final Result discussion}

- Inlet temp of working fluid: $90^{\circ} \mathrm{C}$

- $\quad$ Outlet temp of the working fluid: $41.3621^{\circ} \mathrm{C}$

- $\Delta \mathrm{T}=48.638^{\circ} \mathrm{C}$

- $\quad$ Coolant inlet temperature: $26^{\circ} \mathrm{C}$

- Coolant outlet temperature: $68.321^{\circ} \mathrm{C}$

\section{REFERENCES}

[1] "Heat Transfer Enhancement of Shell and Tube Heat Exchanger" - International Journal for Research in Applied Science and Engineering Technology, Vol. 2 Issue VIII, August 2014, ISSN 2321-9653.

[2] "CFD Analysis to study the effects of inclined baffles on Fluid Flow in a shell and tube Heat Exchanger" - International Journal of Research in Advent Technology, Vol.2, No.7, July 2014, E-ISSN: 2321-9637.

[3] "Optimization of Shell \& Tube Heat Exchanger by Baffle Inclination \& Baffle Cut" - International Journal of Innovative Research in Science, Engineering and Technology, Vol.4, Special Issue 12, September 2015.

[4] "Comparison Of The Cooling Effects Of A Locally Formulated Car Radiator Coolant With Water And A Commercial Coolant"- The International Journal Of Engineering And Science (IJES), Volume 2, Issue 01, January 2013.

[5] "Standards of the tubular exchanger manufactures association" - 9th edition.

[6] "Classification of Heat Exchanger" Pdf.

[7] "Effectively Design Shell-and-Tube Heat Exchangers" - Rajiv Mukherjee, Engineers India Ltd.

[8] "Copper Oxide Nanomaterials Prepared by Solution methods, Some Properties, and Potential Applications" - International Scholarly Research Notices, Volume 2014, Article ID 856592.

\section{BIOGRAPHIES}

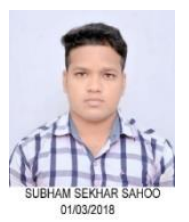

Student - Master of Technology in Power Plant Engineering \& Energy Management, O.P Jindal University, Raigarh , Chhattisgarh. 